\title{
The forensic implications of predatory publishing
}

\author{
Roger W. Byard ${ }^{1}$
}

Accepted: 10 March 2016/Published online: 2 April 2016

(C) Springer Science+Business Media New York 2016

"There are books of which the backs and the covers are by far the best parts" Charles Dickens (1812-1870)

An email that I received recently requested my participation in a conference on "coastal zones" because of my academic standing in the field. It began: "Dear Byard, Greetings for the day! Lets Exploit yourself to the world. Because we believe that 'You are the one that can inspires the common, to change the recitation of emerging world" [sic]. The reality is, however, somewhat different-I have never written or presented a paper on "coastal zones". In fact the only recent experience that I have had of coastal zones is taking my dog for a walk at the beach near Adelaide on weekends. This is hardly an activity to qualify for international pre-eminence, although Lucy (the dog) does seem to enjoy it. The sad fact is that nowadays we all receive persistent marketing emails such as this that are often written in idiosyncratic, hyperbolic, and incorrect English that invite us to be on editorial boards, to write papers, monographs and text books, and to travel to the far reaches of the planet to present at conferences on subjects ranging from oceanographic research to attention deficit disorder. Most, if not all, are in no way related to the specific areas of research or expertise of the recipient. The reason for this is that it is inconsequential to the publishers/ organizers, as long as they can have enough participants/contributors who are who willing to pay the often substantial fees that are charged for involvement in such

Roger W. Byard

roger.byard@sa.gov.au

1 Discipline of Anatomy and Pathology, Level 3 Medical School North Building, School of Medical Sciences, The University of Adelaide, Frome Road, Adelaide 5005, Australia activities. Frankly some of these requests are not too dissimilar to emails that sometimes arrive congratulating the recipient on winning several billion dollars-all that is required are full banking details, including passwords.

In this Editorial I would like to focus on requests for submission for publication in certain online journals, as these have a much darker side. While online publishing clearly involves many quite reputable journals, the proliferation of predatory journals means that nowadays, for a price, anyone can have almost anything published. This has resulted in something resembling a vanity press with authors knowingly using these journals to expand their CVs in order to assist with promotions, grants, and employment [1]. The situation is made worse by the indexing of predatory journals on databases such as Google Scholar, which will inflate the h-indexes of their contributors [2].

To get some idea of the volume of requests that I regularly receive I collected all of the email requests to submit to online journals for a 1-month period commencing on April 1 2015. I included only requests for manuscript submission and excluded all requests to edit textbooks, to be on editorial boards and to attend meetings. Over the following month I identified 49 requests for submissions. Examining the emails or journal websites revealed that it would cost me approximately USD $\$ 52,896$ (and this included some quite generous discounts) to have all of these papers published. So depending on the constraints of departmental or personal resources, I could accrue as many papers as I would want for approximately USD $\$ 1079$ per publication.

Predatory journals use certain techniques to make themselves look credible. One is to have a title or a logo that is very similar to legitimate journals, and to have recognized academics listed on their editorial boards without their knowledge or consent [3]. These journals may 
claim high impact factors that are not derived from recognized sources [4]. Desktop publishing is cheap and widely available nowadays and access to potential contributors is as close as the nearest computer terminal. An analysis of predatory journals showed that there were 18 in 2011, 477 at the end of 2014, and 923 in 2016 (https:// scholarlyoa.com, accessed 6 March 2016) with the majority of those charging APCs (article publishing charges) located in India; other counties include Nigeria, Iran, Turkey, Malaysia, and Pakistan [5-7]. In fact, it has been suggested that there are more "British Journals of..." based in Pakistan than there are in the United Kingdom [8]. Some of these journals may exist for only a matter of weeks [9].

In forensic circles there has always been a problem in dealing with aberrant theories that are at odds with the mainstream literature. In the past this material was often introduced into court without the imprimatur of peer-reviewed, or any, publication. It is now possible with the advent of predatory journals, however, that even the most bizarre theories with inadequate or no scientific validation could be published. To the courts these papers would appear to be no different to those published in legitimate journals, and without a clear knowledge of a particular journal's reputation and process, may be difficult to exclude. My concern is that predatory journals may be used in future to legitimize fringe theories and to validate bogus experts.

Although these journals claim to have a peer review process in place it is unlikely that it involves reputable reviewers in the field. To test this, Bohannon submitted a fabricated paper with flawed design to 304 open access journals and found that over half accepted the paper with no comments on the errors [10]. The lack of peer review has raised the possibility that falsified data, image manipulation and plagiarism has made them "veritable reservoirs of author misconduct" [8].

Another major concern involves junior researchers who may not realize the implications that this type of publishing may have for their future careers. They may even be encouraged by their supervisors to submit their work to these journals in an effort to elevate publication numbers. While this may initially seem like an easy way to build up a $\mathrm{CV}$ it may have the unfortunate effect of publishing material that may not have been considered acceptable if it had been properly peer-reviewed and submitted to a legitimate journal. Also, having these journals listed in CVs may subsequently cast doubt on the academic credibility of the authors. This may be a heavy price to pay for a genuine mistake compounding naivety. It has been found that there is a preponderance of "young inexperienced researchers from developing countries" who elect to publish in these journals [9].
It can sometimes be very difficult to identify a predatory journal, particularly if a paper is produced out of context. To assist with this, Jeffrey Beall, a University of Colorado librarian who coined the term "predatory" for certain open-access publishers, has been producing a list of these journals since 2009 on Scholarly Open Access (https:// scholarlyoa.com, accessed 6 March 2016). He also provides detailed criteria for evaluating journals to determine whether they are predatory or not. Typical features include a lack of contact information with post office boxes often registered in the United States, very rapid turnaround times, persistent flattering email invitations, an editor with no standing in the discipline, and websites with numerous grammatical errors [8].

An interesting variation on the pitfalls of modern publishing for authors that I would like to mention in passing involves "Cram 101", a publishing group that takes bona fide text books and "summarizes" them. My textbook "Sudden Death in the Young, 3rd edition", published by Cambridge University Press in 2010, is available in an abridged form from Cram 101 through Amazon Books [11]. While this is not a predatory journal, it is a book in which my original work has been plagiarized and extensively misquoted without permission from me or the publishers. Here are some of the more disturbing definitions that have been entered by their presumably computergenerated program to illustrate the poor quality of these types of publications:

"Cell": a 2006 horror novel by Stephen king (pg28)

"Shock": (cooking technique), to quickly stop the cooking process of blanched items by plunging them in ice water (pg 180)

"Mellitus": the first Bishop of London in the Saxon period, the third Archbishop of Canterbury, and a member of the Gregorian mission sent to England to convert the Anglo-Saxons from their native paganism to Christianity, $\mathrm{He}$ arrived in $601 \mathrm{AD} \ldots$ (pg 487)

"Normal": a song by the Foo fighters (pg 590)

To further illustrate how these journals operate, Tom Spears, a reporter with the Ottawa Citizen in Canada, had a paper accepted by Experimental and Clinical Cardiology. What was actually submitted was a plagiarized study on HIV in which "HIV" had been replaced with "cardiac", with detailed captions for non-existent graphs and a nonsensical title "VEGF proliferation in cardiac cells contributes to vascular declension". Spears also noted that some published articles in this journal had titles of "Enter paper title" and that the 142 articles published in July 2014 would have netted the journal \$170,000USD [12].

Predatory and unethical publishing on such a global scale is a relatively recent phenomenon designed to bypass 
normal peer-review, to make money for the "publishers" and to create instant CV's for authors. As Bowman points out this has a direct effect by undermining "public trust in the validity of peer-reviewed and scientific publication" [13]. It is also of concern that members of the public seeking information on the internet will have no way of determining how valid the source of (mis)information is. While this strikes at the very heart of traditional academic practice, how we deal with this threat is yet to be established. Also how we identify such publications when they are presented in court or as part of a legal opinion for rapid assessment is another issue that has not yet been widely discussed. My feeling, however, is that we will certainly be afforded this opportunity relatively soon.

\section{References}

1. Bartholomew RE. Science for sale: the rise of predatory journals. J R Soc Med. 2014;107:384-5.

2. Gutierrez FR, Beall J, Forero DA. Spurious alternative impact factors: the scale of the problem from an academic perspective. BioEssays. 2015;. doi:10.1002/bies.201500011.
3. Kearney MH. Predatory publishing: what authors need to know. Res Nurs Health. 2015;38:1-3.

4. Knoll JL. Open access journals and forensic publishing. J Am Acad Psychiatry Law. 2014;42:315-21.

5. Xia J. Predatory journals and their article publishing charges. Learn Pub. 2015;28:69-74.

6. Clark J, Smith R. Firm action needed on predatory journals. Br Med J. 2015;350:h210.

7. Beall J. Predatory publishers are corrupting open access. Nature. 2012;489:179.

8. Beall J. Medical publishing triage-chronicling predatory open access publishers. Ann Med Surg. 2013;2:47-9.

9. Xia J, Harmon JL, Connolly KG, Donnelly RM, Anderson MR, Howard HA. Who publishes in "predatory" journals? J Assoc Inf Sci Technol. 2014;. doi:10.1002/asi.23265.

10. Bohannon J. Who's afraid of peer review? Science. 2013;342:60-5.

11. Byard RW. Study guide for sudden death in the young. CRAM 101. 2013. http://www.amazon.com/Studyguide-Sudden-DeathYoung-Byard/dp/1490202854. Accessed 6 March 2016.

12. Spears T. Respected medical journal turns to the dark side. Ottawa Citizen. 2014. http://ottawacitizen.com/technology/sci ence/respected-medical-journal-turns-to-dark-side. Accessed 6 March 2016.

13. Bowman JD. Predatory publishing, questionable peer review, and fraudulent conferences. Am J Pharm Educ. 2014;78:176. 